\title{
Thermogenic responses to graded doses of noradrenaline in undernourished Indian male subjects
}

\author{
BY A. V. KURPAD, R. N. KULKARNI, M. L. SHEELA AND P. S. SHETTY* \\ Nutrition Research Centre (ICMR), Department of Physiology, St John's Medical \\ College, Bangalore 560034 , India
}

(Received 18 November 1987 - Accepted 11 October 1988)

\begin{abstract}
1. Seventeen male subjects with an energy intake of $10 \cdot 6(\mathrm{SD} \mathrm{1.7)} \mathrm{MJ} / \mathrm{d}$ and ten male undernourished labourers with an energy intake of 8.0 (SD 1.2) $\mathrm{MJ} / \mathrm{d}$ were studied. The controls were subdivided into ten underweight controls with a body mass index (weight/height ${ }^{2} ;$ BMI) $<18(17.2$ (SD 0.9)) and seven normal-weight controls with a BMI > $20(21.3$ (SD 1.6)), while the undernourished labourers had a BMI < $18(16.8$ (sD 1.2)).

2. Comparison of thermogenic responses to increasing doses of noradrenaline showed no overall significant inter-group differences when subjected to a nested analysis of variance (ANOVA). For the initial doses of 0.05 and $0.1 \mu \mathrm{g}$ noradrenaline, significantly lower responses were seen in the undernourished subjects, while the highest dose showed comparable responses in all three groups. Thermogenic responses to the initial two doses, when corrected for fat-free mass (FFM) differences, were $40 \%$ lower in the undernourished group when compared with the underweight group with similar BMI and FFM values. However, this finding was not statistically significant.

3. The basal oxygen consumption of the undernourished group, expressed per unit FFM, was significantly
\end{abstract} higher than that of the controls.

The ability to modulate energy expenditure to compensate for variability in daily energy intake is considered important in the maintenance of body-weight stability (James \& Trayhurn, 1976). In this context, it is useful to consider energy expenditure as being composed of three distinct components, i.e. basal metabolic rate, thermogenesis (which is the increase in oxygen consumption over the basal state in response to factors such as cold exposure or diet) and the energy cost of physical activity (Jéquier, 1984). Adaptation to reduction in energy intakes can occur both by alteration in body size and by metabolic adaptation; the latter by altering total daily energy expenditure. During experimental semistarvation, in addition to loss in body-weight, there is a reduction in the basal metabolic rate which declines by $10 \%$ at 12 weeks (Shetty, 1980) and by up to $15 \%$ at 3 weeks when expressed per unit body-weight (Keys et al. 1950). There is, however, no information with regard to changes, if any, in the thermogenic component of energy output in energyrestricted states. The present study was carried out to estimate the capacity for thermogenesis, as measured by an increase in $\mathrm{O}_{2}$ consumption above the basal state following intravenous infusions of increasing doses of noradrenaline in undernourished subjects compared with normal-weight controls and lean subjects on ad lib. intakes.

\section{MATERIALS AND METHODS}

Subjects

Twenty-seven healthy adult male volunteers were investigated. Ten volunteers were undernourished labourers, drawn from a low socio-economic group resident in a neighbouring slum, who had energy intakes of $<10 \mathrm{MJ} / \mathrm{d}$, as estimated by dietary recall on two occasions, and with body mass indices (weight/height ${ }^{2} ; \mathrm{BMI}$ ) of $<18$. The

* For reprints. 
remaining seventeen subjects were well-nourished controls who were from good socioeconomic backgrounds which permitted normal ad lib. intakes and energy intakes of $>10$ $\mathrm{MJ} / \mathrm{d}$ (dietary recall on two occasions). The control subjects were divided into two subgroups: (a) seven normal-weight controls who had normal body-weights-for-heights and hence BMI $>20$, (b) ten underweight or lean controls who had low body-weights-forheights resulting in comparable BMI to that of the labourers, i.e. BMI $<18$. The undernourished labourers led a physically active life and were involved in manual labour at least $6 \mathrm{~d}$ /week. The control subjects, both normal weight and lean, were either medical students or staff and had daily patterns of activity suggestive of a sedentary to a moderately active life.

\section{Experimental protocols}

Each of the twenty-seven subjects underwent a complete clinical examination before they were recruited for the study. Nutritional status was assessed by anthropometry, i.e. bodyweight, height, skinfolds (using Holtain Skinfold Calipers, Crymmych, UK) and midupper-arm circumference (MAC). Fat-free mass (FFM) was calculated from the sum of four skinfolds (biceps, triceps, subscapular and suprailiac) by applying the formula of Durnin \& Womersley (1974). All subjects, except the labourers, reported to the laboratory in the morning, in the fasting state, while the undernourished labourers stayed overnight in the laboratory, before the day of the experiment. This was done in order to ensure that labourers had their last meal at least 12-14 h before the study and were fasting thereafter. The controls resided in a hostel close to the laboratory and the investigators had constant access to them. The experimental protocol consisted of intravenous (iv) cannulation of both arms using a 20G iv intracath (Critikon Inc, Tampa, USA) and connecting tubes. These were kept patent using sterile $38 \mathrm{~g}$ sodium citrate/ 1 solution. One of the intracaths was used for infusion of noradrenaline and the other for blood collection. A continuous electrocardiogram (ECG) recording was obtained and monitored on an oscilloscope, while a sphygmomanometer cuff attached to the upper arm where the iv line for blood collection was used, served to obtain periodic measurement of arterial blood pressure. The other intracath was connected to a variable-rate infusion pump (Sage Instruments, White Plains, USA) which was previously calibrated.

Every subject was given a $1 \mathrm{~h}$ period of rest after which a ventilated hood system was used to monitor $\mathrm{O}_{2}$ consumption. This incorporated a sealed hood around the subject's head, which was ventilated at a rate of 50 litres fresh air $/ \mathrm{min}$. Both incoming and outgoing air was analysed using a Servomex paramagnetic $\mathrm{O}_{2}$ analyser (Sybron Taylor, Crowborough, UK), an infra-red carbon dioxide analyser (ADC Instruments, Hoddesdon, UK) and a dewpoint hygrometer (General Electric, Watertown, USA) for vapour pressure. The analysers were calibrated using previously calibrated standard gases $\left(201 \mathrm{ml} \mathrm{O}_{2}+9 \mathrm{ml}\right.$ $\mathrm{CO}_{2} / 1$; Indian Oxygen Ltd, Bombay). These variables, along with ambient temperature, were fed into a Solartron minate scanner and voltmeter (Solartron, Farnborough, UK) and interfaced with a computer for immediate on-line analysis (Shetty et al. 1987). The results of $\mathrm{O}_{2}$ consumption were expressed in $1 / \mathrm{min}$ standard temperature and pressure, dry (STPD). Minute-to-minute $\mathrm{O}_{2}, \mathrm{CO}_{2}$, respiratory quotient (RQ) and energy-consumption readings were thus obtained for each subject. After measurement of basal $\mathrm{O}_{2}$ consumption for 30 min continuously, blood samples were obtained for measurement of basal plamsa 3,5,3'-triiodothyronine $\left(T_{3}\right)$, thyroxine $\left(T_{4}\right)$ levels which were estimated using radioimmunoassay (RIA) kits (BARC, Bombay) and free $T_{3}$ by RIA Coat-a-Count Kit (Diagnostic Corp., Los Angeles, USA).

Infusions of three graded doses of noradrenaline (Nordrin, Unichem, Bombay) were 
given for $30 \mathrm{~min}$ each, separated by $1 \mathrm{~h}$ rest between infusions. The doses were given in ascending order of strength, i.e. $0.05,0.1$ and $0.15 \mu \mathrm{g} / \mathrm{kg}$ FFM per min. This provided a standardized dose for all individuals. Heart rate and blood pressure were recorded during each infusion on three occasions, $10 \mathrm{~min}$ apart, while ECG was monitored continuously throughout the experimental period. $\mathrm{O}_{2}$ consumption was averaged for 5 min intervals and the response to noradrenaline was calculated as the mean (cumulative) increment over the baseline during the infusion. The response was also corrected for differences in FFM between the groups. RQ changes were also monitored. In addition, to test for the persistence of effects of the noradrenaline infusion, the baseline $\mathrm{O}_{2}$ consumptions before each infusion were compared in all three groups.

\section{Ethical considerations}

Ethical approval was obtained for the study from a duly constituted human investigation committee of the medical school and all subjects gave fully informed written consent. All precautions were taken including continuous ECG monitoring and immediate availability of anti-arrhythmic drugs. Adequate resuscitative facilities were made available during the duration of the study.

\section{Statistical analysis}

Thermogenic responses and cardiovascular changes to increasing doses of noradrenaline were analysed for intra- and inter-group differences using a two-way nested analysis of variance (ANOVA). In addition an unpaired Student's $t$ test was used to compare mean increment in $\mathrm{O}_{2}$ consumption for each dose between the groups. Comparisons of anthropometric indices, dietary intakes and hormone levels of the different groups were made using an unpaired Student's $t$ test, while comparisons of pre-infusion baselines were made using a paired $t$ analysis. Results are expressed as means (SD), and considered significant if $P<0.05$.

\section{RESULTS}

All subjects were between 19 and 28 years of age. The chronically undernourished subjects were significantly shorter than the control subjects, while the body-weight of the controls was significantly higher than that of the undernourished and underweight subjects (Table 1). The FFM was also the lowest in the undernourished groups, although significant differences in FFM were also seen in underweight controls compared with the normalweight controls. The mean daily energy intakes of 11.2 (SD 1.7) MJ and 10.2 (SD 1.5) MJ in the normal-weight and underweight subjects respectively were comparable, and significantly higher than that of the undernourished labourers, whose intake was 8.0 (SD 1.2) $\mathrm{MJ} / \mathrm{d}$ (Table 2). When energy intake was standardized for FFM, however, the only significant differences seen were between the underweight controls and undernourished subjects. Daily protein intakes showed similar trends, but the protein intake of the undernourished subjects was significantly lower than that of both control groups.

The basal $\mathrm{O}_{2}$ consumption of the undernourished and underweight subjects was lower in absolute terms than that of the normal-weight group, although when expressed per $\mathrm{kg}$ FFM, the undernourished had significantly higher basal $\mathrm{O}_{2}$ consumptions $(+11 \cdot 2 \%)$ compared with both normal-weight and underweight controls. On infusion of noradrenaline there was a significant increase in the $\mathrm{O}_{2}$ consumption over basal levels in all groups of subjects studied. For the two lower doses, $\mathrm{O}_{2}$ consumption rose to a maximum in about $20 \mathrm{~min}$, while for the highest dose used (i.e. $0.15 \mu \mathrm{g}$ ), the maximal consumption of $\mathrm{O}_{2}$ did not appear to be achieved, as there was no plateau in the $\mathrm{O}_{2}$ consumption per min 
A. V. KURPAD AND OTHERS

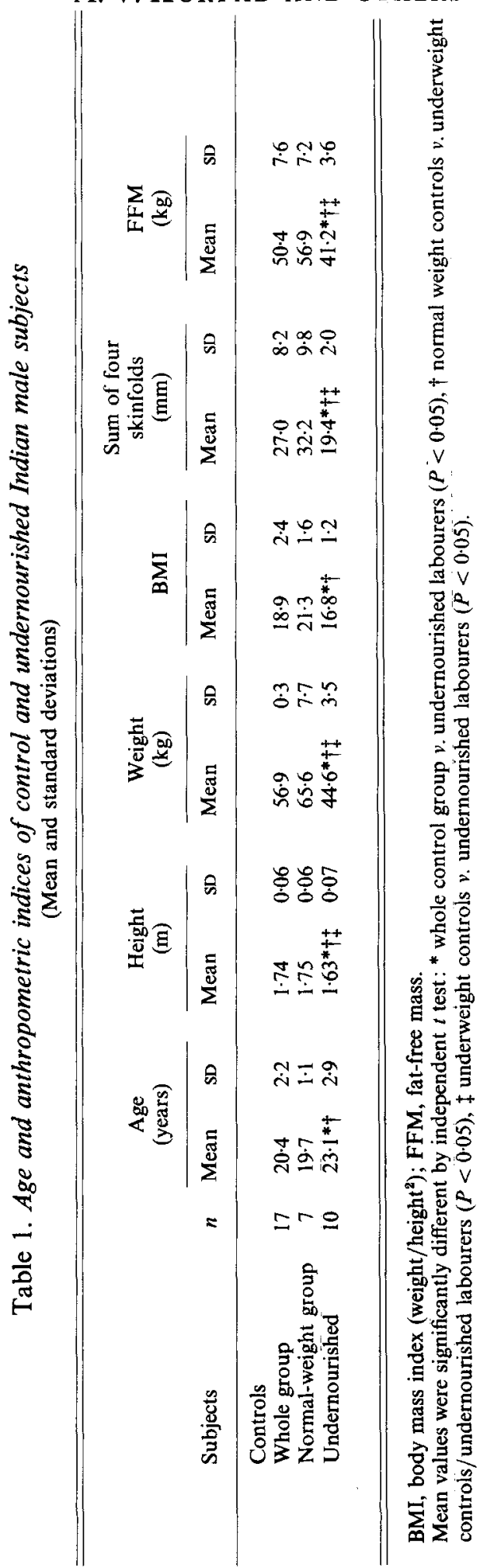


Table 2. Energy and protein intakes and thyroid hormone (3,5,3'-triiodothyronine, $T_{3}$; thyroxine, $T_{4}$ ) status of control and undernourished Indian male subjects

(Means and standard deviations)

\begin{tabular}{|c|c|c|c|c|c|c|c|c|}
\hline & \multicolumn{6}{|c|}{ Controls } & & \\
\hline & \multicolumn{2}{|c|}{$\begin{array}{l}\text { Whole group } \\
(n 17)\end{array}$} & \multicolumn{2}{|c|}{$\begin{array}{l}\text { Normal-weight } \\
\text { group } \\
(n 7)\end{array}$} & \multicolumn{2}{|c|}{$\begin{array}{l}\text { Underweight } \\
\text { group } \\
(n 10)\end{array}$} & \multicolumn{2}{|c|}{$\begin{array}{l}\text { Undernourished } \\
(n 10)\end{array}$} \\
\hline & Mean & SD & Mean & SD & Mean & SD & Mean & SD \\
\hline \multicolumn{9}{|l|}{ Energy intake } \\
\hline $\mathrm{MJ} / \mathrm{d}$ & $10 \cdot 6$ & 1.7 & $11 \cdot 2$ & $2 \cdot 0$ & $10 \cdot 2$ & $1 \cdot 5$ & $8 \cdot 0 *+\ddagger$ & $1 \cdot 2$ \\
\hline $\mathrm{kJ} / \mathrm{kg}$ FFM per d & $211 \cdot 7$ & $34 \cdot 1$ & $198 \cdot 5$ & 35.7 & $220 \cdot 9$ & $31 \cdot 4$ & 191.94 & $28 \cdot 8$ \\
\hline \multicolumn{9}{|l|}{ Protein intake } \\
\hline $\mathrm{g} / \mathrm{d}$ & $73 \cdot 1$ & $20 \cdot 7$ & $79 \cdot 0$ & $24 \cdot 0$ & $68 \cdot 9$ & $18 \cdot 1$ & $42 \cdot 9 *+4$ & $9 \cdot 0$ \\
\hline g/kg FFM per d & $1 \cdot 4$ & $0 \cdot 3$ & 1.4 & $0-4$ & $1 \cdot 5$ & $0 \cdot 3$ & $1 \cdot 0^{*}+ \pm$ & 0.2 \\
\hline \multicolumn{9}{|l|}{ Plasma } \\
\hline Total $\mathrm{T}_{4}(\mu \mathrm{g} / \mathrm{l})$ & $66 \cdot 1$ & $7 \cdot 5$ & $65 \cdot 7$ & $8 \cdot 0$ & $72 \cdot 2$ & $15 \cdot 4$ & $71 \cdot 3$ & $18 \cdot 9$ \\
\hline Total $\mathrm{T}_{3}(\mathrm{ng} / \mathrm{ml})$ & $1 \cdot 0$ & $0 \cdot 2$ & $1 \cdot 0$ & 0.2 & $1 \cdot 1$ & 0.2 & $1 \cdot 2$ & $0 \cdot 2$ \\
\hline Free $\mathrm{T}_{3}(\mathrm{pg} / \mathrm{ml})$ & 2.6 & 0.4 & 2.5 & 0.5 & $2 \cdot 7$ & $0 \cdot 3$ & $2 \cdot 8$ & 0.4 \\
\hline Total $\mathrm{T}_{3}: \mathrm{T}_{4}(\times 100)$ & $1 \cdot 5$ & $0 \cdot 3$ & $1 \cdot 5$ & 0.3 & $1 \cdot 5$ & 0.3 & 1.8 & 0.6 \\
\hline
\end{tabular}

Mean values were significantly different by independent $t$ test: * whole control group $v$. undernourished labourers $(P<0.05)$, $†$ normal weight controls $v$. underweight controls/undernourished labourers $(P<0.05)$, $\ddagger$ underweight controls $v$. undernourished labourers $(P<0.05)$.

at the end of the 30 min period of infusion in all the three groups studied. There was no statistically significant inter-group variation on analysis using nested ANOVA, while the within-group increase in $\mathrm{O}_{2}$ consumption with increasing dose (i.e. dose response) was significant in all three groups of subjects studied. The absolute response of the undernourished subjects was significantly lower (Student's $t$ test) for the two lower doses $(0.05$ and $0.1 \mu \mathrm{g})$ compared with the control groups. These responses to the two lower doses, even when corrected for FFM differences, appeared to be $41.2 \%$ lower for $0.05 \mu \mathrm{g}$ and $45 \%$ lower for $0.1 \mu \mathrm{g}$ in the undernourished than the underweight subjects of similar BMI and nearly comparable FFM. However, these differences were not statistically significant.

The pre-infusion $\mathrm{O}_{2}$ consumption levels (i.e. baseline levels) were also analysed for evidence of persistence of effects of the previous dose of noradrenaline. A paired $t$ test showed significant differences in the baseline levels for each successive infusion in the underweight group only (Table 3). In the normal-weight controls and in the undernourished group, there were no significant differences since the $\mathrm{O}_{2}$ consumption returned to basal levels within the $1 \mathrm{~h}$ period of rest between infusions.

As shown in Table 2, the total $T_{3}, T_{4}$ and free $T_{3}$ values for all groups were similar. The $T_{3}: T_{4}$ value was also calculated and no significant differences were seen between groups. None of the subjects showed increases in blood pressure of more than $50 \mathrm{mmHg}$ over resting values. The highest dose noradrenaline infusions were accompanied by bradycardia ( $40-50$ beats $/ \mathrm{min}$ ) and increases in blood pressure up to a maximum of $40 \mathrm{mmHg}$ above normal. The cardiovascular responses did not show differences between groups on ANOVA, while the within-group change with increasing doses was significant. 
Table 3. Basal and noradrenaline-stimulated oxygen consumptions of control and undernourished Indian male subjects

\begin{tabular}{|c|c|c|c|c|c|c|c|c|c|}
\hline & \multirow{3}{*}{$\begin{array}{c}\text { Noradrenaline } \\
\text { dose } \\
(\mu \mathrm{g} / \mathrm{kg} \text { FFM } \\
\text { per min })\end{array}$} & \multicolumn{6}{|c|}{ Controls } & \multirow{2}{*}{\multicolumn{2}{|c|}{$\begin{array}{l}\text { Undernourished } \\
\qquad(n \text { 10) }\end{array}$}} \\
\hline & & \multicolumn{2}{|c|}{$\begin{array}{l}\text { Whole group } \\
\quad(n 17)\end{array}$} & \multicolumn{2}{|c|}{$\begin{array}{l}\text { Normal-weight } \\
\text { group } \\
(n 7)\end{array}$} & \multicolumn{2}{|c|}{$\begin{array}{l}\text { Underweight } \\
\text { group } \\
(n 10)\end{array}$} & & \\
\hline & & Mean & $\mathrm{SD}$ & Mean & SD & Mean & SD & Mean & SD \\
\hline \multicolumn{10}{|l|}{ Basal $\mathrm{O}_{2}$ consumption } \\
\hline $\begin{array}{l}\mathrm{ml} / \mathrm{min} \\
\text { FFM }\end{array}$ & & $4 \cdot 37$ & 0.43 & $4 \cdot 31$ & 0.57 & $4 \cdot 41$ & $0 \cdot 34$ & $4 \cdot 86^{*}+\frac{1}{!}$ & 0.43 \\
\hline \multicolumn{10}{|c|}{$\begin{array}{l}\text { Mean increment in } V_{\mathrm{O}_{2}} \\
\text { Dose } 1\end{array}$} \\
\hline $\mathrm{ml} / \mathrm{min}$ & & $11 \cdot 5$ & $5 \cdot 5$ & $12 \cdot 3$ & $5 \cdot 0$ & $10 \cdot 9$ & $6 \cdot 0$ & $5 \cdot 7 *+4$ & $4 \cdot 0$ \\
\hline $\mathrm{ml} / \mathrm{min}$ per $\mathrm{kg}$ & & 0.235 & 0.126 & 0.231 & $0 \cdot 101$ & 0.237 & $0 \cdot 132$ & $0 \cdot 142$ & $0 \cdot 101$ \\
\hline $\begin{array}{l}\text { FFM percentage } \\
\text { increase over } \\
\text { basal level }\end{array}$ & $0 \cdot 10$ & $5 \cdot 21$ & $2 \cdot 55$ & $5 \cdot 04$ & $2 \cdot 20$ & $5 \cdot 31$ & $2 \cdot 88$ & $2 \cdot 80 *+t$ & 1.91 \\
\hline \multicolumn{10}{|l|}{ Dose 2} \\
\hline $\mathrm{ml} / \mathrm{min}$ & & $17 \cdot 2$ & $11 \cdot 1$ & $17 \cdot 6$ & $7 \cdot 7$ & $16 \cdot 9$ & $13 \cdot 4$ & $9 \cdot 1^{*} \dagger$ & $5 \cdot 9$ \\
\hline $\mathrm{ml} / \mathrm{min}$ per $\mathrm{kg}$ & & $0 \cdot 346$ & 0.242 & 0.313 & $0 \cdot 136$ & 0.370 & $0 \cdot 300$ & $0 \cdot 225$ & $0 \cdot 145$ \\
\hline $\begin{array}{l}\text { FFM percentage } \\
\text { increase over } \\
\text { basal level }\end{array}$ & $0 \cdot 15$ & $7 \cdot 81$ & $5 \cdot 50$ & $7 \cdot 40$ & $3 \cdot 33$ & $8 \cdot 10$ & $6 \cdot 79$ & $4 \cdot 77$ & $2 \cdot 97$ \\
\hline \multicolumn{10}{|l|}{ Dose 3} \\
\hline $\mathrm{ml} / \mathrm{min}$ & & 26.8 & $12 \cdot 3$ & $27 \cdot 9$ & $10 \cdot 1$ & $25 \cdot 9$ & $14 \cdot 3$ & $23 \cdot 1$ & 9.6 \\
\hline $\mathrm{ml} / \mathrm{min}$ per $\mathrm{kg}$ & & 0.536 & $0 \cdot 256$ & 0.504 & 0.206 & 0.561 & $0 \cdot 300$ & 0.558 & 0.215 \\
\hline $\begin{array}{l}\text { FFM percentage } \\
\text { increase over } \\
\text { basal level }\end{array}$ & & $11 \cdot 57$ & $5 \cdot 31$ & $11 \cdot 46$ & $4 \cdot 86$ & 11.66 & 5.93 & $10 \cdot 88$ & $3 \cdot 86$ \\
\hline \multicolumn{10}{|l|}{$\begin{array}{l}\text { Pre-infusion basal } \mathrm{O}_{2} \\
\text { consumption }(\mathrm{ml} / \mathrm{min})\end{array}$} \\
\hline Dose 2 & $0 \cdot 10$ & $227 \cdot 5$ & $25 \cdot 0$ & $244 \cdot 0$ & 19.8 & $212 \cdot 2$ & $17 \cdot 6$ & $190 \cdot 9$ & $21 \cdot 1$ \\
\hline Dose 3 & 0.15 & $233 \cdot 3$ & $24 \cdot 4$ & 247.9 & $15 \cdot 7$ & $221 \cdot 9 * *+\dagger$ & $23 \cdot 0$ & $210 \cdot 3$ & $19 \cdot 2$ \\
\hline
\end{tabular}

FFM, fat-free mass; $V_{\mathrm{O}_{2}}$, oxygen consumption.

Mean values were significantly different; unpaired $t$ test : * whole control group $v$. undermourished labourers ( $P$ $<0.05)$, $†$ normal weight controls $v$. underweight control/undernourished labourers $(P<0.05)$, $\ddagger$ underweight controls $v$. undernourished labourers $(P<0.05)$. Paired $t$ test for basal $\mathrm{O}_{2}$ consumption: $* *$ dose $1 v$. dose $3(P$ $<0.05)$, $\dagger \dagger$ dose $2 v$. dose $3(P<0-05)$.

\section{DISCUSSION}

When lower than acceptable levels of energy intakes are associated with life-styles demanding a high degree of physical activity, a reduction in energy expenditure must occur in order to maintain body-weight. As an adaptive response to this reduction in intake of energy, one may expect a reduction in one or more of the three components of energy output, i.e. basal metabolism, thermogenesis and physical activity (Jéquier, 1984). The present study demonstrates that there appears to be a significant reduction in the response to noradrenaline-stimulated thermogenesis between normal-weight or underweight controls and undernourished subjects for the initial doses infused. With the higher doses, the rise in noradrenaline-stimulated $\mathrm{O}_{2}$ consumption increases in the undernourished subjects and hence the differences seen earlier tend to disappear. The added effect of the inability of the 
maximum $\mathrm{O}_{2}$ consumption response to attain peak levels with the highest dose $(0.15 \mu \mathrm{g})$ during the $0.5 \mathrm{~h}$ of infusion (Sheela et al. 1988) makes the inter-group differences in the dose responses disappear when examined by a nested ANOVA.

The significantly lower absolute $\mathrm{O}_{2}$ utilization responses seen in the undernourished subjects for similar initial doses of noradrenaline infused per $\mathrm{kg} \mathrm{FFM}$, also appeared to be reduced by over $40 \%$ even when corrected for FFM differences (Table 3 ). However, this difference was not statistically significant, largely due to the inherent variability in the individual responses seen in the different groups. This degree of variability in individual responses to noradrenaline infusion may have been further aggravated by the lack of precision in the measurements of FFM from the sum of four skinfolds using regression equations. Durnin \& Womersley (1974) have reported that in one-third of their male subjects the error in prediction of body fat from skinfolds was greater than $5 \%$ of the bodyweight. These inaccuracies may contribute to the responses when corrected for FFM, having even larger ranges of variability, thus making the results appear not significant. The equations of Durnin \& Womersley (1974) are not universally applicable (Norgan \& FerroLuzzi, 1985). It has been shown that they tend to underestimate the FFM of Indian subjects by over $9.0 \%$ (Avadhany \& Shetty, 1986); the error may be even higher in the undernourished subjects with low skinfolds since these equations are not wholly linear and tend to deviate even further from the true values at the extreme ends of the regression line. This may explain why the basal $\mathrm{O}_{2}$ consumption of the undernourished appeared to be significantly higher than that of the normal-weight controls and may also contribute to reducing the differences between these groups when values for noradrenaline-stimulated $\mathrm{O}_{2}$ consumption are corrected for the estimated FFM differences.

An increase in resting $\mathrm{O}_{2}$ consumption expressed per unit FFM does not necessarily imply that there is an altered metabolic efficiency of the tissues in the undernourished. The metabolically active tissue mass of the body is made up of different proportions of tissues of widely different levels of metabolic activity (Brozeck, 1955), each of which contributes to the resting $\mathrm{O}_{2}$ consumption to an extent unrelated to their contribution to FFM (Holliday et al. 1967). It is possible that a change in the proportions of different components can bring about a change in the average resting $\mathrm{O}_{2}$ consumption of the total FFM. The reduction in the less active muscle tissue mass, as indicated by the lower MAC of the undernourished, relative to the reduction in active visceral mass, such as liver, may result in resting $\mathrm{O}_{2}$ consumption appearing higher than normal in the undernourished when expressed per $\mathrm{kg}$ FFM.

Though the view that thermogenesis may play an important role in the regulation of body-weight or body energy stores of animals is well documented (Trayhurn \& James, 1981 ; James et al. 1987), unequivocal evidence that this is so in human beings is lacking. Most recent studies have not been able to demonstrate differences between lean and obese human subjects when dose responses to noradrenaline, using similar protocols to those of the present study, were compared (Welle \& Campbell, 1983; Katzeff et al. 1986). In the only study where differences have been demonstrated between lean and obese women (both before and after weight loss), dose responses to noradrenaline were not obtained (Jung et al. 1979). In this study, the increase in $\mathrm{O}_{2}$ consumption was measured, following a single 45 min infusion of noradrenaline in a dose based on ideal body-weight which produced nearly similar levels of plasma noradrenaline. The initial infusion may in some manner influence the subsequent response in the same subject (Kurpad et al. 1988) such that differences may appear with single infusions (as in the study by Jung et al. (1979), or with the initial dose, in the present study) but not with dose-response studies (Welle $\&$ Campbell, 1983; Katzeff et al. 1986). This seems to be the case, at least in the present study, since the percentage differences between the undernourished and underweight controls, who were 
anthropometrically comparable, decreased from $40 \%$ with the lowest dose to $10 \%$ with the highest dose infused.

It may be concluded that long-term adjustments in energy requirements in developing countries may be achieved not only by adjustments in spontaneous physical activity and by slow but significant changes in body-weight (James \& Shetty, 1982), but also possibly by an adaptive reduction in thermoregulatory thermogenesis. As yet, there is no evidence to suggest that such an adaptive response during prolonged marginal restriction in intakes of energy is anything but a small component of the whole adaptive process in undernutrition, since the apparent differences in noradrenaline-stimulated thermogenesis correspond to between 2 and $3 \%$ of the basal energy expenditure.

The study was supported by The Nestlé Foundation, Switzerland. The indirect calorimetry apparatus was financed by a grant-in-aid from The Wellcome Trust, UK.

\section{REFERENCES}

Avadhany, S. T. \& Shetty, P. S. (1986). Determination of total body water in vivo by ethanol dilution in man. Indian Journal of Medical Research 84, 217-222.

Brozek, J. (1955). Nutrition and behaviour; psychologic changes in acute starvation with hard physical work. Journal of the American Dietetic Association 31, 77-92.

Durnin, J. V. G. A. \& Womersley, J. (1974). Body fat assessed from total body density and its estimation from skinfold thickness; measurements on 481 men and women aged 16-72 years. British Journal of Nutrition 32, 77-92.

Holliday, M. A., Potter, D., Jarrah, A. \& Bearg, S. (1967). The relation of metabolic rate to body weight and organ size. Pediatric Research 1, 185-195.

James, W. P. T. \& Shetty, P. S. (1982). Metabolic adaptation and energy requirements in developing countries. Human Nutrition: Clinical Nutrition 36C, 331-336.

James, W. P. T. \& Trayhurn, P. (1976). The metabolic basis of subnormal thermogenesis in obesity. Lancet ï, 770-772.

James, W. P. T., Trayhurn, P. \& Garlick, P. (1987). An integrated view of the metabolic and genetic basis for obesity. In Recent Advances in Obesity Research vol. 3, pp. 220-227 [P. Bjorntorp, M. Cairella and A. N. Howard, editors]. London: John Libbey.

Jéquier, E. (1984). Energy expenditure in obesity. Clinical Endocrinology and Metabolism 13, 563-580.

Jung, R. T., Shetty, P. S. \& James, W. P. T. (1979). Reduced thermogenesis in obesity. Nature 279, 322-323.

Katzeff, H. L., O'Connel, N., Horton, E. S., Danforth E. Jr, Houng, J. B. \& Landsberg, L. (1986). Metabolic studies in human obesity during over nutrition and undernutrition; thermogenic and hormonal responses to NE. Metabolism 35, 166-175.

Keys, A., Brozeck, J., Henschel, A., Mickelson, O. \& Taylor, H. B. (1950). The Biology of Human Starvation. Minneapolis: University of Minnesota Press.

Kurpad, A. V., Kulkarni, R. N. \& Shetty, P. S. (1988). Potentiation of thermogenic responses during norepinephrine infusions in human subjects. Medical Science Research 16, 997-998.

Norgan, N. G. \& Ferro-Luzzi, A. (1985). The estimation of body density in man: are general equations general? Annals of Human Biology 12, 1-15.

Sheela, M. L., Kurpad, A. V., Kulkarni, R. N. \& Shetty, P. S. (1988). Prediction of steady state oxygen consumption during norepinephrine infusions in man. Metabolism 37, 907-909.

Shetty, P. S. (1980). Studies on protein and energy restriction and dietary thermogenesis in obesity and chronic undernutrition. PhD Thesis, University of Cambridge.

Shetty, P. S., Sheela, M. L., Murgatroyd, P. R. \& Kurpad, A. V. (1987). An open-circuit indirect whole body calorimeter for the continuous measurement of energy expenditure of man in the tropics. Indian Journal of Medical Research 85, 453-460.

Trayhurn, P. \& James, W. P. T. (1981). Thermogenesis: dietary and non-dietary aspects. In The Body Weight Regulatory System: Normal and Disturbed Mechanisms, pp. 97-105 [L. A. Cioff, W. P. T. James and T. B. Van Itallie, editors]. New York: Raven Press.

Welle, S. \& Campbell, R. G. (1983). Studies of thermogenesis by carbohydrate overfeeding. Evidence against sympathetic nervous system activation. Journal of Clinical Investigation 72, 916-925. 